\title{
Comparison of mixotrophic to cyclic autotrophic/heterotrophic growth strategies to optimize productivity of Chlorella sorokiniana
}

van Wagenen, Jonathan Myerson; De Francisci, Davide; Angelidaki, Irini

Published in:

Journal of Applied Phycology

Link to article, DOI:

10.1007/s10811-014-0485-1

Publication date:

2015

Document Version

Publisher's PDF, also known as Version of record

Link back to DTU Orbit

Citation (APA):

van Wagenen, J. M., De Francisci, D., \& Angelidaki, I. (2015). Comparison of mixotrophic to cyclic

autotrophic/heterotrophic growth strategies to optimize productivity of Chlorella sorokiniana. Journal of Applied Phycology, 27(5), 1775-1782. https://doi.org/10.1007/s10811-014-0485-1

\section{General rights}

Copyright and moral rights for the publications made accessible in the public portal are retained by the authors and/or other copyright owners and it is a condition of accessing publications that users recognise and abide by the legal requirements associated with these rights.

- Users may download and print one copy of any publication from the public portal for the purpose of private study or research.

- You may not further distribute the material or use it for any profit-making activity or commercial gain

- You may freely distribute the URL identifying the publication in the public portal 


\title{
Comparison of mixotrophic to cyclic autotrophic/heterotrophic growth strategies to optimize productivity of Chlorella sorokiniana
}

\author{
Jon Van Wagenen • Davide De Francisci • \\ Irini Angelidaki
}

Received: 28 July 2014 / Revised and accepted: 23 November 2014 / Published online: 24 December 2014

(C) Springer Science+Business Media Dordrecht 2014

\begin{abstract}
In addition to providing cheap or free mineral nutrients, wastewaters may contain organic carbon compounds that could increase productivity of algal cultures. This study defined a strategy for the addition of organic carbon to photobioreactors in order to improve their productivity compared to autotrophic growth. Chlorella sorokiniana was cultivated in medium supplemented with sodium acetate in concentrations equivalent to the volatile fatty acid concentration found in anaerobic digester effluent. Flat-panel photobioreactors were operated using 16:8 light:dark cycles, with different strategies for acetate addition. Acetate was added during the light period for the mixotrophic strategy and during the dark one for the cyclic autotrophic/ heterotrophic strategy. Autotrophic productivity of up to $0.99 \mathrm{~g} \mathrm{~L}^{-1}$ day $^{-1}$ was obtained using the optimal tested dilution rate of $0.031 \mathrm{~h}^{-1}$. The highest mixotrophic productivity was $1.04 \mathrm{~g} \mathrm{~L}^{-1} \mathrm{day}^{-1}$. When a constant dilution rate was applied throughout the day, cyclic heterotrophy/autotrophy $\left(1.2 \mathrm{~g} \mathrm{~L}^{-1}\right.$ day $\left.^{-1}\right)$ showed higher productivity than during mixotrophic growth, while using only half as much acetate. By diluting and adding acetate only during the eight dark hours, a maximal productivity of $1.6 \mathrm{~g} \mathrm{~L}^{-1}$ day $^{-1}$ was obtained. Whenever acetate was added, lutein and chlorophyll content decreased, but overall lutein productivity increased. Carotene also increased during the cyclic treatment. These results show that dilution and carbon addition during the dark period resulted in an increased efficiency of the photobioreactor.
\end{abstract}

Electronic supplementary material The online version of this article (doi:10.1007/s10811-014-0485-1) contains supplementary material, which is available to authorized users.

J. Van Wagenen · D. De Francisci · I. Angelidaki $(\bowtie)$

Department of Environmental Engineering, Technical University of

Denmark, DTU Environment Building 113, 2800 Kgs., Lyngby,

Denmark

e-mail: Iria@env.dtu.dk
Keywords Cyclic autotrophic/heterotrophic $\cdot$ Mixotrophic Chlorella sorokiniana $\cdot$ Chlorophyta $\cdot$ Biorefinery $\cdot$ Lutein . Carotenoid

\section{Introduction}

Microalgae are a potential future source of biofuels and a current source of more valuable products (Wijffels and Barbosa 2010). One way to economize microalgae cultivation is to use waste streams for water and nutrients (Pittman et al. 2011). Municipal waste streams and anaerobic digestion (AD) effluents represent two of the most available and more frequently researched streams for biomass production and concomitant nutrient removal with microalgae treatment (Lundquist et al. 2010; Cai et al. 2013a). In these cases, the waste stream is mostly viewed as a source of macronutrients ( $\mathrm{N}$ and $\mathrm{P}$ ) and micronutrients (such as trace metals), while organic carbon removal is mostly treated as a negligible by-product of the basically autotrophic process. AD effluent has typically high turbidity and high $\mathrm{N}$ content which makes significant dilution necessary (Cai et al. 2013b), while treated municipal effluent, if not concentrated, presents low organic nutrient load (Li et al. 2012).

Recently, several investigations have focused on other waste streams with high organic carbon content which could result in high biomass productivity through heterotrophic or mixotrophic growth (see Table 1). These studies proved that in some cases, it could be beneficial to even pre-treat the waste streams to increase the organic carbon content; Hu et al. (2012), for example, used acidogenic fermentation of swine manure for this purpose.

Organic carbon can be used along with sunlight in microalgal bioprocesses in different ways. In mixotrophic growth, it is used during the day together with the light, while in heterotrophic growth, the organic carbon is used instead of ight, but may reduce the cellular content of desirable pigments 
Table 1 Residual organic sources tested for mixotrophic or heterotrophic microalgae cultivation

\begin{tabular}{|c|c|c|}
\hline $\begin{array}{l}\text { Waste type and carbon } \\
\text { sources }\end{array}$ & $\begin{array}{l}\text { Organic } \\
\text { concentration } \\
\left(\mathrm{g} \mathrm{L}^{-1}\right)\end{array}$ & Reference \\
\hline Industrial dairy waste & & (Abreu et al. 2012) \\
\hline Lactose & 10 & \\
\hline Glucose & 5 & \\
\hline Galactose & 5 & \\
\hline $\begin{array}{l}\text { Soybean processing } \\
\text { wastewater }\end{array}$ & & (Hongyang et al. 2011) \\
\hline VFA & 2.5 & \\
\hline Synthetic wastewater & & (Lopez et al. 2010) \\
\hline Glucose & 10 & \\
\hline Acetate & 2.5 & \\
\hline Acidogenically digested manure & & (Hu et al. 2012) \\
\hline VFA & $3-7$ & \\
\hline Synthetic biodiesel plant effluent & & (Cabanelas et al. 2013) \\
\hline Glycerol & $0.56-4.6$ & \\
\hline Food waste hydrolysate & & (Pleissner et al. 2013) \\
\hline Glucose & $2.6-18.5$ & \\
\hline Synthetic wastewater & & (Lim et al. 2013) \\
\hline Acetate & $<0.255$ & \\
\hline Synthetic wastewater & & (Moon et al. 2013) \\
\hline Acetate or VFA & $\leq 10$ & \\
\hline
\end{tabular}

(Kobayashi et al. 1992). A cyclic autotrophic/heterotrophic strategy is also possible, where organic carbon is added only during the dark (Ogbonna and Tanaka 1998). This strategy is attractive because it turns the night from a time of biomass loss to dark respiration to a time of biomass production (Ogbonna and Tanaka 1996). Furthermore, continuous autotrophic/ heterotrophic processes may be classified as those in which medium is added to the cultures continuously during the light phase to maintain an optimal culture density and the ones in which feed (and harvest) take place only during the dark phase to maximize the input of organic carbon source.

In this study, mixotrophic and cyclic heterotrophic/ autotrophic growth during continuous photobioreactor cultivation of Chlorella sorokiniana were compared. Acetate was chosen as the organic carbon source as it is the most common volatile fatty acid (VFA) produced during anaerobic digestion processes and is therefore in excess in $\mathrm{AD}$ effluents. The aim was to maximize volumetric productivity $\left(\mathrm{g} \mathrm{L}^{-1} \mathrm{day}^{-1}\right)$ given fixed light and acetate inputs representative of high surface area to volume photobioreactors operated on wastewaters. Quantification of the efficiency of photosynthesis $Y_{X, L}$ $\left(\mathrm{g} \mathrm{mol}^{-1}\right)$ and carbon utilization $\mathrm{Y}_{\mathrm{X}, \mathrm{A}}\left(\mathrm{g} \mathrm{g}^{-1}\right)$ are critical outputs. Additionally, the cellular composition of pigments was assayed under the tested conditions, as pigments represent the most valuable component of the algal biomass (Borowitzka 2013).

\section{Materials and methods}

Chlorella sorokiniana CCAP 211/8 K stock culture was maintained in modified M8a medium on a shaker table under continuous illumination of fluorescent bulbs of approximately $50 \mu \mathrm{mol}$ photons $\mathrm{m}^{-2} \mathrm{~s}^{-1}$ as in Cuaresma et al. (2009). Sodium acetate (Sigma) was used at different concentrations for the experiments. Cultures were maintained at strictly $20{ }^{\circ} \mathrm{C}$. Dry weight was obtained by filtering cultures onto pre-weighed Whatman GFF filters followed by drying in an oven at $95^{\circ} \mathrm{C}$ for at least $18 \mathrm{~h}$.

\section{Microplates}

Microplates (PE VISIPLATE, 24 well black-walled, clearbottomed) were used to compare the effect of acetate concentration on mixotrophic and heterotrophic growth. Mixotrophic microplates were inoculated at non-self-shading low culture densities $\left(\mathrm{OD}_{750}<0.1\right)$ and monitored by fluorescence in a BIOTEK synergy scanner (440 nm emission, $690 \mathrm{~nm}$ detection). Mixotrophic cultures were illuminated by LED at $150 \mu \mathrm{mol}$ photons $\mathrm{m}^{-2} \mathrm{~s}^{-1}$ during a 12:12 light:dark cycle and shaken at $160 \mathrm{rpm}$ with a $50 \mathrm{~mm}$ throw. Cultivations, well-top membranes, growth rate calculations, and detection limits were as described in Van Wagenen et al. (2014). Heterotrophic cultures were performed at higher starting concentration $\mathrm{OD}_{750}=1$. They were cultivated on the same shaker but wrapped in aluminum foil to maintain darkness and with membranes punctured to allow better exchange of gases. Scans were taken up to eight times daily.

\section{Photobioreactors}

Two "Algaemist" photobioreactors were built at Wageningen University and consisted of a 1.4-cm panel, $22.5-\mathrm{cm}$ high, and $13-\mathrm{cm}$ wide with rounded edges and working volume of $400 \mathrm{~mL}$ (Figure S1). The culture temperature was maintained by a heat jacket, and illumination was provided by six LEDs with a cool white spectrum. Temperature was controlled near the species optimum at $37 \pm 0.5^{\circ} \mathrm{C}$. Aeration of $400 \mathrm{~mL} \mathrm{~min}^{-1}$ air was used for airlift mixing, and carbon dioxide was provided on demand to maintain a $\mathrm{pH}$ of $7.0 \pm 0.3$. Data from light sensors placed in front and behind the reactors was logged continuously using a custom script in LABVIEW. Dilution for continuous experiments was done via a timed peristaltic pump at rates from $6-26 \mathrm{~mL} \mathrm{~min}^{-1}$. 


\section{Cultivation experiments}

Photobioreactors were inoculated from the stock cultures with initial $\mathrm{OD}_{750}$ of 0.2 and operated as autotrophic batches under a 16:8 light:dark cycle with ca. $200 \mu \mathrm{mol}$ photons $\mathrm{m}^{-2} \mathrm{~s}^{-1}$ until density reached $1 \mathrm{~g} \mathrm{~L}^{-1}$. At this point, the two reactors were operated for two different experimental sets at different dilution rates, with each dilution rate applied for a minimum of 4 days to reach stable growth. Four growth strategies were applied: (1) autotrophy, with medium supplied only during the light period, (2) mixotrophy with dilution only during the light period, (3) cyclic autotrophy/heterotrophy with a constant dilution rate throughout the day, (4) cyclic autotrophy/ heterotrophy with medium supplied only during the dark
Fig. 1 Schematic of representative a light intensity, b dilution rate, and $\mathbf{c}$ acetate addition rate for each of the cultures strategies
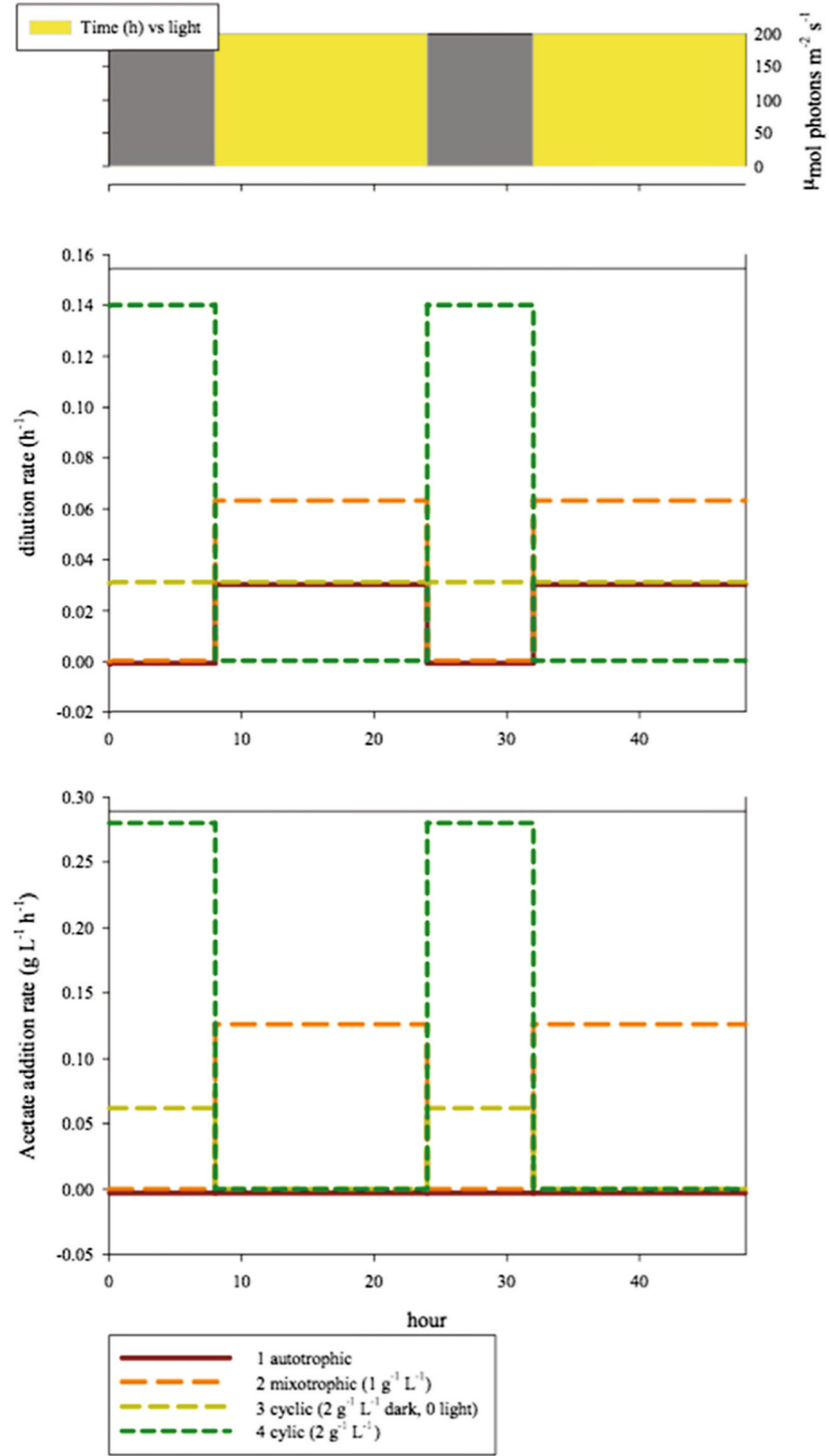
period. A schematic of these strategies is given (Fig. 1). A magnet was used to disrupt wall growth at the beginning and end of every dark period. Reactors were sterilized and reinoculated between runs.

Measurement of respiratory biomass loss during the night was performed the day before and after the transition from autotrophic to cyclic. On day 8, the culture in reactor 3 was transitioned from autotrophic to heterotrophic by adding medium containing acetate in the dark period. As a control, for the same dark period, reactor 1 was diluted with acetate-free medium to observe the changes in density caused by wall biofilm formation rather than dark respiration.

\section{Calculations}

Dilution rate (D) was calculated by dividing daily volume of effluent collected $\left(\mathrm{L} \mathrm{day}^{-1}\right)$ by reactor volume (L). Rate of acetate addition $\left(\mathrm{q}_{\mathrm{A}}\right)$ was calculated by multiplying the substrate concentration $\left(\mathrm{S}_{\mathrm{A}}\right)$ by the dilution rate. Biomass concentration $\left(\mathrm{X}_{\mathrm{AV}}\right)$ was the average dry weight $\left(\mathrm{g} \mathrm{L}^{-1}\right)$ throughout the given run period and was obtained by averaging the $\mathrm{OD}_{750}$ values and multiplying by a correlation value $\left(0.22 \mathrm{~g} \mathrm{~L}^{-1} \mathrm{OD}\right.$ unit $\left.^{-1}, R^{2}>0.98\right)$. Volumetric productivity $\left(\mathrm{P}_{\mathrm{V}}, \mathrm{g} \mathrm{L}^{-1}\right.$ day $\left.^{-1}\right)$ was the measured sum the daily increase of biomass in the reactor with the biomass collected in the effluent bottle per $\mathrm{L}$ of reactor. Photosynthetic yield $\left(\mathrm{Y}_{\mathrm{X}, \mathrm{L}}\right)$ was calculated:

$Y_{\mathrm{X}, \mathrm{L}}=\frac{\mathrm{P}_{V} * V}{I * A}$

where $V$ is the volume of the reactor $(0.4 \mathrm{~L})$ and $A$ is the area of the reactor $\left(0.02925 \mathrm{~m}^{2}\right)$ and $I$, the incident light is given in the units mol photons day ${ }^{-1}$. This calculation purposefully does not include energy from the acetate, so that increases relative to typically achieved photosynthetic yields can be seen. Apparent yield on acetate ( $\mathrm{Y}_{\mathrm{X}, \mathrm{A}}$ app.) was calculated as:

$$
Y_{A} \text { app. }=\frac{\mathrm{P}_{V} * V}{q_{A}}
$$

while corrected yield on acetate $\left(\mathrm{Y}_{\mathrm{X}, \mathrm{A}}\right.$ corr. $)$ was calculated as:

$Y_{A}$ corr. $=\frac{\left(\mathrm{P}_{V}-P_{A V}\right) * V}{q_{A}}$

where $P_{A V}$ is the average photosynthetic productivity of trials optimal autotrophic runs $1 \mathrm{~d}, 1 \mathrm{e}$, and 1f.

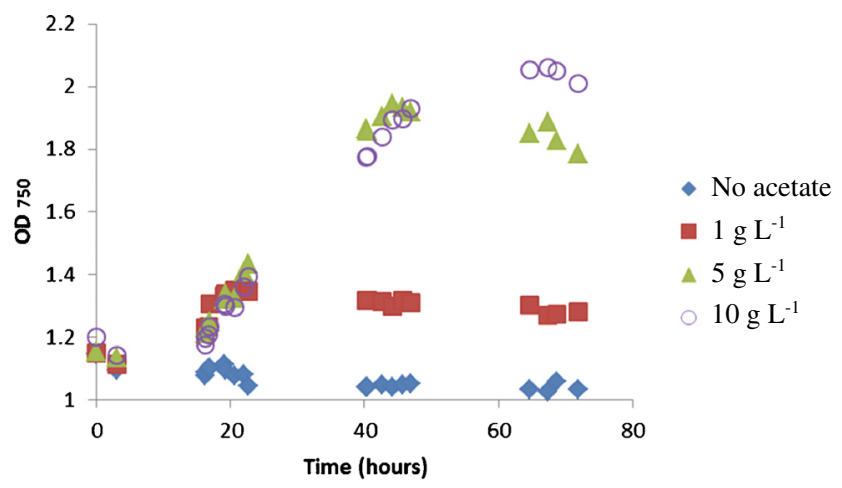

Fig. 2 Plot of $\mathrm{OD}_{750}$ vs. time for grown C. sorokiniana on various concentrations of sodium acetate in dark, heterotrophic microplate experiments. Average of 5 replicates

\section{Acetate removal}

Acetate removal was measured during batch cultivation. Liquid was separated from cells using a $2 \mu \mathrm{m}$ filter. Quantification relied on HPLC using the VFA method of Huang et al. (2008) with $30 \mathrm{~min}$ retention time. A $0.3 \mathrm{M}$ $\mathrm{NaOH}$ trap of $50 \mathrm{~mL}$ volume was applied to the reactor effluent gas to detect any volatilized acetic acid.

\section{Pigments}

Extraction was performed using $2 \mathrm{mg}$ freeze-dried biomass in $3 \mathrm{~mL} 90 \%$ acetone. Cells were disrupted with a Potter-Elvehjem tissue grinder and shaken in the dark for $1 \mathrm{~h}$. Residual biomass was collected by centrifuge and re-extracted in $1 \mathrm{~mL} 90 \%$ acetone. A Zorbax Eclipse plus C8 RRHD $1.8 \mu \mathrm{m} 3.0 \times 150 \mathrm{~mm}$ column was used for UHPLC separation at $60{ }^{\circ} \mathrm{C}$ with a $75 \mathrm{~min}$ separation time. Detection utilized UV-VIS at $450 \mathrm{~nm}$. Quantification was done relative to individual pigment standards obtained from DHI, Hørsholm, diluted from 15 to $1500 \mu \mathrm{g} \mathrm{L}{ }^{-1}$.

\section{Results}

Low density microplate cultures showed that growth in medium with $1 \mathrm{~g} \mathrm{~L}^{-1}$ acetate resulted in a significant increase of the growth rate $(p<0.001)$ compared to autotrophic growth (Table 2). The exponential growth rate measured during the

Table 2 Comparison of daytime and overall specific growth rate for low-density mixotrophic microplate cultures

\begin{tabular}{lll}
\hline Condition & Autotrophic & Mixotrophic $\left(1 \mathrm{~g} \mathrm{~L}{ }^{-1}\right.$ acetate $)$ \\
\hline Daytime growth rate \pm standard deviation $\left(\right.$ day $\left.^{-1}\right)$ & $1.01 \pm 0.37(n=12)$ & $1.67 \pm 0.41(n=18)$ \\
Overall growth rate day and night \pm standard deviation $\left(\right.$ day $\left.^{-1}\right)$ & $0.65 \pm 0.053(n=4)$ & $1.62 \pm 0.14(n=6)$ \\
\hline
\end{tabular}


Table 3 Removal of acetate in batch photobioreactors, under $200 \mu \mathrm{mol} \mathrm{m}{ }^{-2} \mathrm{~s}^{-1} 12: 12$ light:dark cycle, $T=37^{\circ} \mathrm{C}$ initial biomass concentration 1.9 $2.2 \mathrm{~g} \mathrm{~L}^{-1}$

\begin{tabular}{llllll}
\hline Trial no. & $\begin{array}{l}\text { Lighting } \\
\text { conditions }\end{array}$ & $\begin{array}{l}\text { Initial acetate } \\
\text { concentration } \\
\left(\mathrm{g} \mathrm{L}^{-1}\right)\end{array}$ & $\begin{array}{l}\text { Removal rate } \\
\left(\mathrm{g} \mathrm{L}^{-1} \mathrm{day}^{-1}\right)\end{array}$ & $R^{2}$ & $\begin{array}{l}\text { Rate during } \\
\text { first 30 min } \\
\left(\mathrm{g} \mathrm{L}^{-1} \mathrm{day}^{-1}\right)\end{array}$ \\
\hline A & Light to dark & 2.27 & 12.0 & 0.992 & 5.10 \\
$\mathrm{~A} 1$ & Light & 2.27 & 11.5 & 0.998 & 5.10 \\
$\mathrm{~A} 2$ & Dark & 0.73 & 13.0 & 0.998 & na \\
B & Light & 1.06 & 12.9 & 0.954 & 1.42 \\
\hline
\end{tabular}

light period was 1.55 times higher than the average rate during both light and dark periods for autotrophic growth, indicating as expected that increase in chlorophyll density was mostly growth-associated. During mixotrophic growth, the ratio was 1.03 which indicates that the culture grew at nearly the same rate during the light and dark periods in this experiment. At low culture densities, Na-acetate concentrations $\geq 5 \mathrm{~g} \mathrm{~L}^{-1}$ were found inhibitory and no growth was observed; higher starting cell densities enabled heterotrophic growth in the presence of 1,5 , or $10 \mathrm{~g}$ acetate $\mathrm{L}^{-1}$, (Fig. 2). All cultures supplemented with acetate began increasing in density within $18 \mathrm{~h}$ of inoculation, and those supplemented with 5 and $10 \mathrm{~g} \mathrm{~L}^{-1}$ continued to grow even after $40 \mathrm{~h}$, with the final density clearly related to acetate concentration.

Acetate removal occurred at a maximum rate of $13 \mathrm{~g} \mathrm{~L}^{-1}$ day $^{-1}$ and at slower rates only during a minimal lag phase which was observable $30 \mathrm{~min}$ after spiking the reactor with sodium acetate (Table 3). These rates of uptake exceeded the rate of addition during all continuous experiments (Table 4). No acetate/acetic acid was detectable in the base trap of gas leaving the reactor indicating that biological uptake was responsible for removal.

In both strategies 1 and 3 , culture density decreased with the increase of the dilution rate (Fig. 3a). When the cyclic strategy was implemented, biomass was harvested at night and this eventually resulted in reactor 3 yielding more biomass than reactor $1(3 \mathrm{~b})$. The amount of light not absorbed by the algae suspension (3c) seems to increase towards the end of each light cycle, probably due to the temporary decrease in algal concentration caused by the formation of small flocs and by wall attachment. This apparent reduction in density was also observed during the detailed dark-phase measurements (3d). Despite wall attachment during the night, during day 8 , it was observed that dilution with acetate led to more biomass produced at the end of the dark period compared to dilution with mineral medium only

Table 4 Kinetic parameters of continuous autotrophic, mixotrophic, and cyclic autotrophic/heterotrophic growth of C. sorokiniana in 16:8 light:dark cycle with ca. $200 \mu \mathrm{mol}$ photons $\mathrm{m}^{-2} \mathrm{~s}^{-1}, T=37^{\circ} \mathrm{C}$

\begin{tabular}{|c|c|c|c|c|c|c|c|c|c|c|}
\hline & No. & $\begin{array}{l}\mathrm{D}_{1} \\
\left(\mathrm{~h}^{-1}\right)\end{array}$ & $\begin{array}{l}D_{d} \\
\left(h^{-1}\right)\end{array}$ & $\begin{array}{l}\mathrm{S}_{\mathrm{A}} \\
\left(\mathrm{g} \mathrm{L}^{-1}\right)\end{array}$ & $\begin{array}{l}\mathrm{X}_{\mathrm{Av}} \\
\left(\mathrm{g} \mathrm{L}^{-1}\right)\end{array}$ & $\begin{array}{l}\mathrm{q}_{\mathrm{A}} \\
\left(\mathrm{g}_{\mathrm{day}}{ }^{-1}\right)\end{array}$ & $\begin{array}{l}\mathrm{P}_{\mathrm{V}} \\
\left(\mathrm{g} \mathrm{L}^{-1} \text { day }^{-1}\right)\end{array}$ & $\begin{array}{l}Y_{X, A} \text { app. } \\
\left(\mathrm{g} \mathrm{g}^{-1}\right)\end{array}$ & $\begin{array}{l}Y_{X, A} \text { corr. } \\
\left(\mathrm{g} \mathrm{g}^{-1}\right)\end{array}$ & $\begin{array}{l}\mathrm{Y}_{\mathrm{X}, \mathrm{L}} \\
\left(\mathrm{g} \mathrm{mol}^{-1}\right)\end{array}$ \\
\hline \multirow[t]{6}{*}{ Autotrophic } & 1a & 0.016 & - & - & 0.98 & - & 0.50 & - & - & 0.64 \\
\hline & $1 \mathrm{~b}$ & 0.016 & - & - & 1.08 & - & 0.53 & - & - & 0.64 \\
\hline & $1 \mathrm{c}$ & 0.031 & - & - & 1.39 & - & 0.76 & - & - & 0.97 \\
\hline & $1 d$ & 0.031 & - & - & 1.49 & - & 0.69 & - & - & 0.84 \\
\hline & 1e & 0.031 & - & - & 1.40 & - & 0.99 & - & - & 1.27 \\
\hline & 1f & 0.047 & - & - & 0.84 & - & 0.81 & - & - & 1.04 \\
\hline \multirow[t]{2}{*}{ Mixotrophic } & $2 \mathrm{a}$ & 0.034 & - & 1 & 1.54 & 0.220 & 0.72 & 1.31 & -0.16 & 0.93 \\
\hline & $2 b$ & 0.063 & - & 1 & 1.53 & 0.405 & 1.04 & 1.03 & 0.23 & 1.34 \\
\hline \multirow{2}{*}{$\begin{array}{l}\text { Cyclic-constant dilution } \\
\text { rate }\end{array}$} & $3 a$ & 0.031 & 0.031 & 2 & 1.50 & 0.200 & 1.18 & 2.36 & 0.74 & 1.44 \\
\hline & $3 b$ & 0.047 & 0.047 & 2 & 1.01 & 0.300 & 1.08 & 1.45 & 0.36 & 1.32 \\
\hline \multirow{2}{*}{$\begin{array}{l}\text { Cyclic-enhanced night } \\
\text { heterotrophic }\end{array}$} & $4 a$ & - & 0.094 & 2 & 1.67 & 0.602 & 1.33 & 0.88 & 0.34 & 1.61 \\
\hline & $4 b$ & - & 0.140 & 2 & 1.47 & 0.899 & 1.57 & 0.70 & 0.34 & 1.91 \\
\hline
\end{tabular}

$D$ dilution rate, $l$ light period, $d$ dark period, $S_{A}$ acetate substrate concentration, $X_{A v}$ average biomass concentration, $q_{A}$ rate of acetate addition, $P_{V}$ volumetric productivity, $Y_{X, A}$ yield on acetate, app. apparent or corr. corrected by subtracting autotrophic growth, $Y_{X, L}$ app apparent photosynthetic yield 

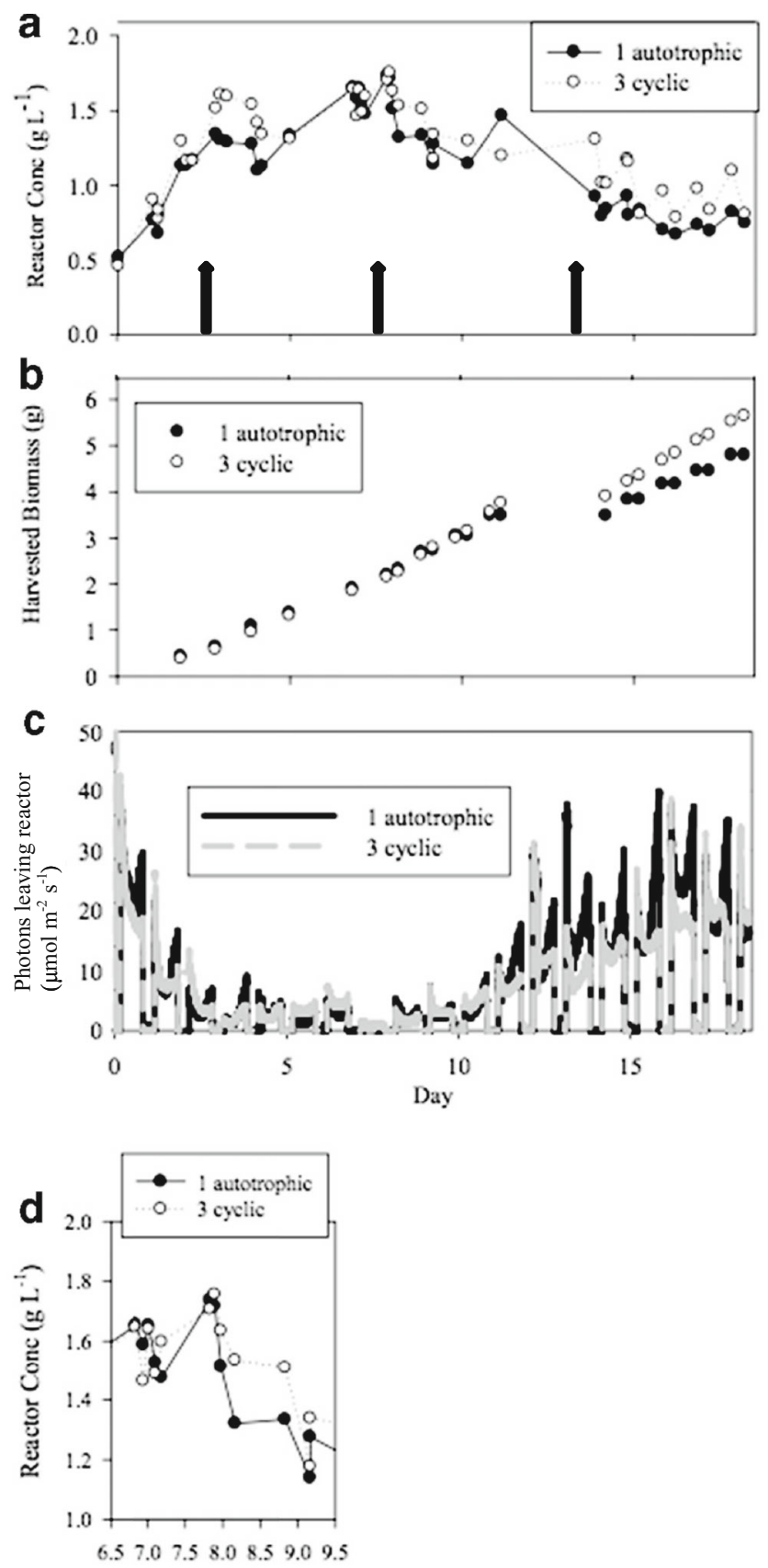

Fig. 3 Plots of culture density (a) cumulative harvest (b) and light exiting the photobioreactors operated under strategies 1 (autotrophic) and 3 (cyclic autotrophic/heterotrophic with constant dilution rate). Changes in culture conditions were indicated with arrows. The sequence of dilution rates was $0.016,0.031,0.031$, and $0.047 \mathrm{~h}^{-1}$. Reactor 3 transitioned from autotrophic to cyclic after the second arrow. (d) Detail of density when shifting from autotrophic to cyclic in reactor 3 and diluting reactor 1

(3d). The changes in density imposed by the cyclic strategy are even more pronounced in the fourth strategy (Fig. 4).

Pigment content in mixotrophic or cyclic cultures was less than autotrophic cultures, with lutein and chlorophyll being

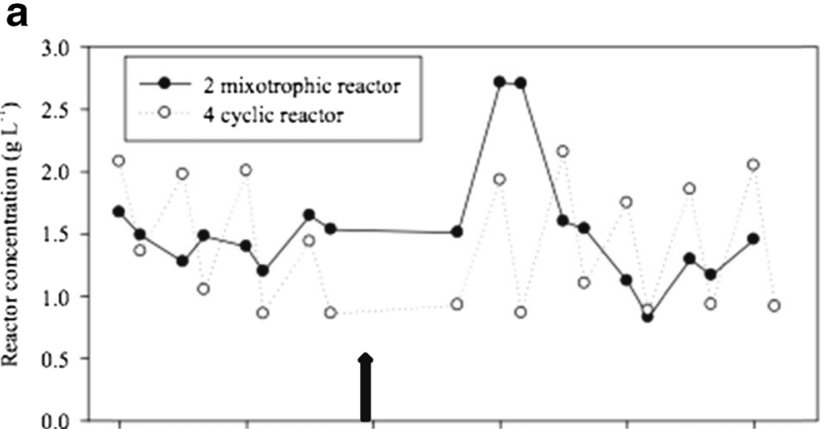

b

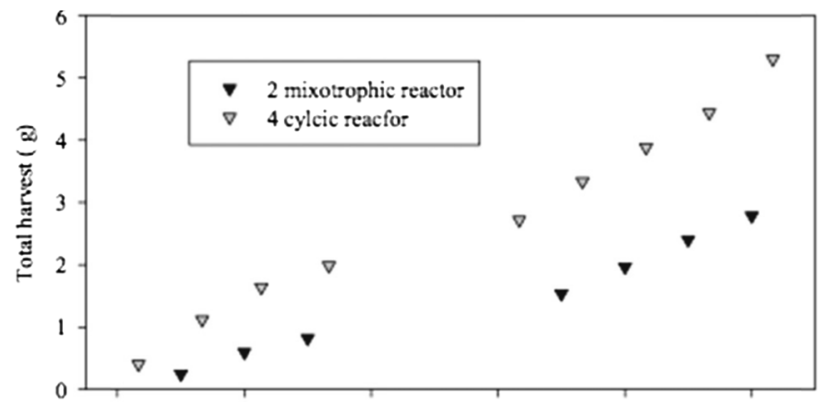

c

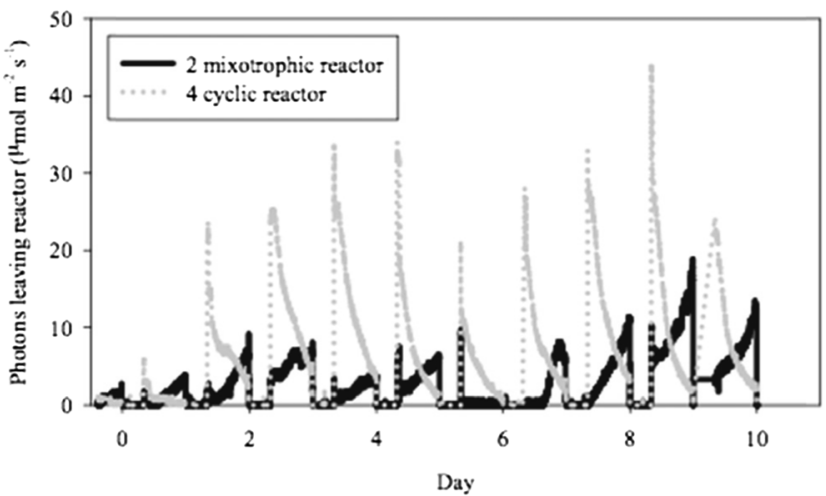

Fig. 4 Plots of culture density (a) cumulative harvest (b) and light exiting the photobioreactors operated under strategies 2 (autotrophic) and 4 (cyclic autotrophic/heterotrophic with constant only during darkness). Change in treatment period are indicated with arrows. The dilution rates for reactor 2 were $0.034,0.063,40.094$, and $0.140 \mathrm{~h}^{-1}$ in reactor 4

reduced by the same proportion. A notable exception was $\alpha$ and $\beta$-carotene, which increased under cyclic conditions (Table 5).

\section{Discussion}

In lab and pilot scale studies (Fernández Sevilla et al. 2004; Lim et al. 2013), algal growth was observed during their night period when substrate was remaining from mixotrophic cultures. The use of mixotrophic growth of Chlorella in outdoor cultures on acetate or acetic acid has even been practiced industrially in Japan (Iwamoto 2004). The literature on these cultivations does not indicate that 
Table 5 Pigment content $\left(\mathrm{mg} \mathrm{g}^{-1}\right)$ in biomass cultivated under different strategies

\begin{tabular}{lcccccccccc}
\hline & Chl a & Chl b & Lutein & Viol & Asta & Fuc & Zea & $\alpha+\beta$ carotene & Total Chl & Total Car. \\
\hline Autotrophic (1f) & 17.76 & 6.23 & 1.76 & 0.03 & 0.28 & 0.45 & 0.14 & 0.50 & 3.16 \\
Mixotrophic (2b) & 10.13 & 3.28 & 1.07 & 0.02 & 0.17 & 0.28 & 0.09 & 0.30 & 23.99 \\
Cyclic (3b) & 11.41 & 3.05 & 1.16 & nd & 0.31 & 0.35 & nd & 1.46 & 13.40 & 14.46 \\
\hline
\end{tabular}

Chl chlorophyll, Viol violaxanthin, Asta astaxanthin, Fuco fucoxanthin, Zea zeaxanthin, Car carotenoids

the cyclic strategy of Ogbonna and Tanaka (1998) has been attempted. The results presented here offer insights into the advantages of cyclic compared to purely mixotrophic growth.

The measured yields give good indication of process performance. Yield of photosynthesis $\left(\mathrm{Y}_{\mathrm{X}, \mathrm{L}}\right)$ has a theoretical maximum based on empirical observation of 1 mol of oxygen gas per 8 mol of photons (Pirt 1986), a given stoichiometry of $\mathrm{O}_{2}$ produced per Cmol of biomass and a formula weight of a $\mathrm{C}$-mol which is relatively stable across algal biomass (Cuaresma et al. 2009). Hence, when acetate was added, the $Y_{X, L}$ exceeded the current practical and theoretical limits to photosynthesis, (1.3 and $1.8 \mathrm{~g} \mathrm{~mol}^{-1}$, respectively) (Cuaresma et al. 2009; Cuaresma et al. 2011). This is an obvious indication of growth caused by factors besides photosynthesis, i.e., growth from consuming the acetate.

Mixotrophic (condition 2b) $\mathrm{Y}_{\mathrm{X}, \mathrm{L}}$ was marginally higher than autotrophic. The small increase over autotrophy could be explained by the prevention of typical night losses of 10 $15 \%$ (Ogbonna and Tanaka 1996). However, the presence of acetate may reduce photosynthetic efficiency (Heifetz et al. 2000) even if overall yield is still boosted by the carbon source. Therefore, it is unsurprising that the highest yields corresponded to the cyclic autotrophic/heterotrophic approach which also maximized the amount of acetate added to the reactor (4b, Table 4). In case $4 b$, the highest $Y_{X, L}$ of 1.91 was obtained. This indicates that maximizing acetate addition into the system was the most productive strategy, even though it also resulted in light being wasted in the morning and probably being limiting by the late afternoon (Fig. 4c). Comparisons of volumetric productivity to other studies of $C$. sorokiniana cultures also show the potential of the cyclic approach. Cuaresma et al. (2011) used a 14-h variable photon flux averaging that totaled $9 \%$ more photons $\mathrm{m}^{-2}$ day $^{-1}$ in a comparably dimensioned reactor and achieved $1.33 \mathrm{~g} \mathrm{~L}^{-1}$ day $^{-1}$.

The biomass yield on acetate $\left(\mathrm{Y}_{\mathrm{X}, \mathrm{A}}\right.$, corr. Table 4) varied from 0.34 to $0.36 \mathrm{~g} \mathrm{~g}^{-1}$ across the three highest diluting cyclic strategies, which is in the expected range for heterotrophic yields of green algae on acetate 0.26 to $0.41 \mathrm{~g} \mathrm{~g}^{-1}$ (Boyle and Morgan 2009) and (Kobayashi et al. 1992), respectively. The $Y_{X, A}$ higher value obtained in condition $3 \mathrm{a}$ suggests possible interacting effects taking place, whereby enhanced yields on light due to optimal cell density may increase the apparent yield on a very small amount of added carbon.

The availability of organic carbon generally leads to a decrease in the chlorophyll content and to changes in other pigments (Ogawa and Aiba 1981; Kobayashi et al. 1992). In this study, the addition of acetate led to a decrease in lutein content, in contrast to the batch studies of Cordero et al. (2011). However, the $34 \%$ reduction in lutein content could be overcome by the observed 1.6 to 2 -fold increase in overall volumetric productivity. Cyclic cultivation boosted the production of $\alpha$ and $\beta$ carotene, whose content increased in along with biomass productivity. Carotenoid production is considered evidence of protection from photodamage, often induced in oxidative stress (Malanga and Puntarulo 1995), environmental conditions, or nutrient starvation (Gouveia 1996). The cyclic treatment's 16-h batch cycle may have induced larger shocks to the culture compared to those in which continuous dilution kept conditions more constant (Bar et al. 1995).

In commercial cultures using acetate, bacterial contamination was noted, but reported algal yields on carbon still remained over $0.25 \mathrm{~g} \mathrm{~g}^{-1}$ (Iwamoto 2004). Such contaminations are likely the main reason why promising reports (Lee et al. 1996) using costly glucose have not been up-scaled; the sterilization of the large surface areas and many connection points required to effectively allow light into a photobioreactor is a considerable challenge compared to a typical steel fermentation tank (Walter et al. 2003). Thus, the gains in productivity in mixotrophic strategies using expensive sugars will be offset by more stringent sterility demands. Further research is needed to determine if the periodic availability of the organics in a cyclic strategy could play a significant role in favoring mixotrophic algae growth rather than unwanted heterotrophs. When low-cost or waste carbon sources are used, bacteria could be beneficial by promoting algal growth by oxidizing organic matter and thereby supplying $\mathrm{CO}_{2}$ to algae for photosynthesis (Bai et al. 2014). Therefore, in systems which are carbon limited, the cyclic strategy may be inferior to conventional mixotrophy.) 
The evidence presented here suggests that cyclic autotrophic/heterotrophic growth deserves further consideration for processes in which a waste-generated VFA is available. A cyclic strategy can boost volumetric productivity and enable 24-h harvesting, eventually leading to a more efficient utilization of compounds often present in wastewaters.

\section{References}

Abreu AP, Fernandes B, Vicente AA (2012) Mixotrophic cultivation of Chlorella vulgaris using industrial dairy waste as organic carbon source. Bioresour Technol 118:61-66

Bai X, Lant P, Pratt S (2014) The contribution of bacteria to algal growth by carbon cycling. Biotechnol Bioeng. doi:10.1002/bit.25475

Bar E, Rise M, Vishkautsan M, Arad SM (1995) Pigment and structural changes in Chlorella zofingiensis upon light and nitrogen stress. J Plant Physiol 146:527-534

Borowitzka MA (2013) High-value products from microalgae - their development and commercialisation. J Appl Phycol 25:743-756

Boyle NR, Morgan JA (2009) Flux balance analysis of primary metabolism in Chlamydomonas reinhardtii. BMC Syst Biol 3:4

Cabanelas ITD, Ruiz J, Arbib Z, Chinalia FA, Garridi-Pérez C, Rogalla F, Nasciamento IA, Perales JA (2013) Comparing the use of different domestic wastewaters for coupling microalgal production and nutrient removal. Bioresour Technol 131:429-436

Cai T, Ge X, Park SY, Li Y (2013a) Comparison of Synechocystis sp. PCC6803 and Nannochloropsis salina for lipid production using artificial seawater and nutrients from anaerobic digestion effluent. Bioresour Technol 144:255-260

Cai T, Park SY, Racharaks R, Li Y (2013b) Cultivation of Nannochloropsis salina using anaerobic digestion effluent as a nutrient source for biofuel production. Appl Energy 108:486-492

Cordero BF, Obraztsova I, Couso I, Leon R, Vargas MA, Rodriguez H (2011) Enhancement of lutein production in Chlorella sorokiniana (Chorophyta) by improvement of culture conditions and random mutagenesis. Mar Drugs 9:1607-1624

Cuaresma M, Janssen M, Vílchez C, Wijffels RH (2009) Productivity of Chlorella sorokiniana in a short light-path (SLP) panel photobioreactor under high irradiance. Biotechnol Bioeng 104:352-359

Cuaresma M, Janssen M, Vílchez C, Wijffels RH (2011) Horizontal or vertical photobioreactors? How to improve microalgae photosynthetic efficiency. Bioresour Technol 102:5129-5137

Fernández Sevilla JM, Cerón García MC, Sánchez Mirón A, Belarbi EH, García Camacho F, Molina Grima E (2004) Pilot-plantscale outdoor mixotrophic cultures of Phaeodactylum tricornutum using glycerol in vertical bubble column and airlift photobioreactors: studies in fed-batch mode. Biotechnol Prog 20:728-736

Gouveia L (1996) Evolution of pigment composition in Chlorella vulgaris. Bioresour Technol 57:157-159

Heifetz PB, Förster B, Osmond CB, Giles LJ, Boynton JE (2000) Effects of acetate on facultative autotrophy in Chlamydomonas reinhardtii assessed by photosynthetic measurements and stable isotope analyses. Plant Physiol 122:1439-1445

Hongyang S, Yalei Z, Chunmin Z et al (2011) Cultivation of Chlorella pyrenoidosa in soybean processing wastewater. Bioresour Technol 102:9884-9890

Hu B, Min M, Zhou W, Du Z, Mohr M, Chen P, Zhu J, Cheng Y, Liu Y, Ruan R (2012) Enhanced mixotrophic growth of microalga
Chlorella sp. on pretreated swine manure for simultaneous biofuel feedstock production and nutrient removal. Bioresour Technol 126 : 71-79

Huang L, Zeng RJ, Angelidaki I (2008) Electricity production from xylose using a mediator-less microbial fuel cell. Bioresour Technol 99:4178-4184

Iwamoto H (2004) Industrial production of microalgal cell-mass and secondary products - major industrial species: Chlorella. In: Richmond A (ed) Microalgal culture: biotechnology and applied phycology. Blackwell Science, Oxford, pp 255-263

Kobayashi M, Kakizono T, Yamaguchi K, Nishio N, Nagai S (1992) Growth and astaxanthin formation of Haematococcus pluvialis in heterotrophic and mixotrophic conditions. J Ferment Bioeng 74:17-20

Lee Y-K, Ding S-Y, Hoe C-H, Low C-S (1996) Mixotrophic growth of Chlorella sorokiniana in outdoor enclosed photobioreactor. J Appl Phycol 8:163-169

Li Y, Zhou W, Hu B, Min M, Chen P, Ruan RR (2012) Effect of light intensity on algal biomass accumulation and biodiesel production for mixotrophic strains Chlorella kessleri and Chlorella protothecoide cultivated in highly concentrated municipal wastewater. Biotechnol Bioeng 109:2222-2229

Lim CY, Chen C-L, Wang J-Y (2013) A strategy for urban outdoor production of high-concentration algal biomass for green biorefining. Bioresour Technol 135:175-181

Lopez N, Bocchi M, Bertin L et al (2010) Volatile fatty acids as the feedstock for lipidic algal biomass producing processes. J Biotechnol 150:173-173

Lundquist T, Woertz I, Quinn N, Benemann J (2010) A realistic technology and engineering assessment of algae biofuel production. Energy Biosciences Institute - University of California, Berkeley, California, pp 1-153

Malanga G, Puntarulo S (1995) Oxidative stress and antioxidant content in Chlorella vulgaris after exposure to ultraviolet-B radiation. Physiol Plant 94:672-679

Moon M, Kim CW, Park W-K, Yoo G, Choi Y-E, Yang J-W (2013) Mixotrophic growth with acetate or volatile fatty acids maximizes growth and lipid production in Chlamydomonas reinhardtii. Algal Res 2:352-357

Ogawa T, Aiba S (1981) Bioenergetic analysis of mixotrophic growth in Chlorella vulgaris and Scenedesmus acutus. Biotechnol Bioeng 23: $1121-1132$

Ogbonna JC, Tanaka H (1996) Night biomass loss and changes in biochemical composition of cells during light/dark cyclic culture of Chlorella pyrenoidosa. J Ferment Bioeng 82:558-564

Ogbonna J, Tanaka H (1998) Cyclic autotrophic/heterotrophic cultivation of photosynthetic cells: a method of achieving continuous cell growth under light/dark cycles. Bioresour Technol 65:65-72

Pirt SJ (1986) The thermodynamic efficiency (quantum demand) and dynamics of photosynthetic growth. New Phytol 102:3-37

Pittman JK, Dean AP, Osundeko O (2011) The potential of sustainable algal biofuel production using wastewater resources. Bioresour Technol 102:17-25

Pleissner D, Lam WC, Sun Z, Lin CSK (2013) Food waste as nutrient source in heterotrophic microalgae cultivation. Bioresour Technol 137:139-146

Van Wagenen J, Holdt SL, De Francisci D, Valverde-Pérez B, Plósz BG, Angelidaki I (2014) Microplate-based method for high-throughput screening of microalgae growth potential. Bioresour Technol 169:566-572

Walter C, Steinau T, Gerbsch N, Buchholz R (2003) Monoseptic cultivation of phototrophic microorganisms-development and scale-up of a photobioreactor system with thermal sterilization. Biomol Eng 20:261-271

Wijffels RH, Barbosa MJ (2010) An outlook on microalgal biofuels. Science 329:796-799 